\title{
Prolyl hydroxylase 2 (PHD2) inhibition protects human renal epithelial cells and mice kidney from hypoxia injury
}

\author{
Yi Fang ${ }^{1,2,3, *}$, Hui Zhang ${ }^{1,4, *}$, Yihong Zhong ${ }^{1}$ and Xiaoqiang Ding ${ }^{1,2,3}$ \\ ${ }^{1}$ Department of Nephrology, Zhongshan Hospital, Fudan University, Shanghai, China \\ ${ }^{2}$ Shanghai Institute of Kidney and Dialysis, Shanghai, China \\ ${ }^{3}$ Shanghai Key Laboratory of Kidney and Blood Purification, Shanghai, China \\ ${ }^{4}$ Department of Nephrology, The Affiliated Hospital of Qingdao University, Qingdao, China \\ * These authors have contributed equally to this work \\ Correspondence to: Xiaoqiang Ding, email: ding.xiaoqiang@zs-hospital.sh.cn \\ Keywords: prolyl hydroxylase 2; hypoxia inducible factor; renal ischemia-reperfusion injury; autophagy and apoptosis; Pathology \\ Section \\ Received: June 14, 2016 \\ Accepted: July 19, 2016 \\ Published: August 05, 2016
}

\section{ABSTRACT}

Prolyl hydroxylase domain protein 2 (PHD2) is a key oxygen sensor, setting low steady-state level of hypoxia-inducible factor-a (HIF-a). Here, we showed that treatment of cobalt chloride $\left(\mathrm{CoCl}_{2}\right)$, a hypoxia mimic, in $\mathrm{HK}-2$ tubular epithelial cells induced PHD2 and HIF-1/2a expression as well as cell apoptosis and autophagy activation. Three methyladenine (3-MA), the autophagy inhibitor, blocked autophagy and protected $\mathrm{HK}-2$ cells from $\mathrm{CoCl}_{2}$. Significantly, siRNA knockdown of PHD2 also protected $\mathrm{HK}-2$ cells from $\mathrm{CoCl}_{2}$, possibly via increasing HIF-1a expression. Reversely, HIF-1a siRNA knockdown almost abolished cytoprotection by PHD2 siRNA in $\mathrm{CoCl}_{2}-$ treated HK-2 cells. In vivo, pretreatment with a PHD inhibitor L-mimosine remarkably attenuated mice renal ischemia-reperfusion injuries. Molecularly, L-mimosine inhibited apoptosis and inflammatory responses in injured mice kidneys. Together, our results suggest that PHD2 silence or inhibition protects human renal epithelial cells and mice kidney from hypoxia injuries.

\section{INTRODUCTION}

Acute kidney injury (AKI) is a deterioration of renal function over a period of hours to days [1, 2]. It will cause severe morbidity if not handled properly $[1,2]$. Ischemichypoxia injury is the major pathological mechanism of AKI [1-4]. Hypoxia-inducible factor- $1 \alpha(\mathrm{HIF}-1 \alpha)$ is a key regulator in adaptation to low oxygen availability [3-5]. It promotes the transcription of many genes involved in cellular and systemic responses to hypoxia [5, 6]. Under normoxia, HIF-1 $\alpha$ is degraded by the prolyl-4-hydroxylase domain (PHD) family proteins, which require di-oxygen and 2-oxoglutarate as co-substrates [7].

Thus far three different PHDs have been identified, including PHD1, PHD2, and PHD3 [4, 8]. PHDs have different but sometime overlapping functions. PHD2 is the critical oxygen sensor of HIF-1 $\alpha$ in normoxia and hypoxia $[8,9]$. The characteristics of theses enzymes provide potential targets for small molecule manipulation, which could activate HIF in the presence of normoxia. For example, cobalt chloride $\left(\mathrm{CoCl}_{2}\right)$ and other iron chelators have been applied to activate HIFs [10, 11]. Existing evidences have shown that enhancing HIF via PHD inhibition could protect against ischemic injuries [11, 12].

Maintaining normal Kidney function requires a high blood flow and a high glomerular filtration rate (GFR) [13]. Additionally, the proximal tubules need large amount of energy in the process of electrolyte re-absorption [13]. The proximal tubules are thus particularly vulnerable to ischemia and/or hypoxia. Ischemic injury is often an integration of multiple complex pathological processes, including apoptosis and autophagy [13].

Autophagy occurs at basal level in most tissues and contributes to the routine turnover of cytoplasmic components $[14,15]$. However, autophagy can also be induced by nutrient deprivation or starvation $[14,15]$. In addition to turnover of cellular components, autophagy is also essential for cell homeostasis [16], as well as cell adaptation and defense to adverse environments $[17,18]$. Studies have highlighted the importance of autophagy 
in normal proximal tubule function and recovery from acute ischemic injuries [19-21]. Paradoxically, chronic activation of autophagy may also promote cell damage [19-21].

In the study, we employed the human renal proximal tubular epithelial cell line $\mathrm{HK}-2$, as well as a mouse model of renal ischemia-reperfusion injury to explore the potential function of PHD2 in the process.

\section{RESULTS}

PHD2 and HIFa expressions are increased in HK-2 tubular epithelial cell after $\mathrm{CoCl}_{2}$ treatment

$\mathrm{CoCl}_{2}$ mimics the hypoxic condition and has been validated as a simple tool to examine the molecular mechanisms driven by hypoxia in vitro [10]. As shown in Figure 1, protein and mRNA expressions of HIF-1 $\alpha$ and HIF-2 $\alpha$ were low under normoxic conditions. After $\mathrm{CoCl}_{2}$ treatment, there was a time-dependent increase of HIF-1/2 $\alpha$ expression at the mRNA level (Figure 1A). A similar pattern of protein expression was observed by Western blot assay (Figure 1B). The protein expression of HIF- $1 \alpha$ and HIF- $2 \alpha$ both significantly increased, starting from $12 \mathrm{~h}(P<0.05$ vs. "0h") (Figure 1B). Whereas HIF$1 \alpha$ and HIF-2 $\alpha$ mRNA expressions were induced at later periods (starting from 24h) (Figure 1A). The protein and mRNA levels of HIF- $1 \alpha$ reached the peak at $36 \mathrm{~h}(P<0.01$ $v s$. "Oh"), which then declined (Figure 1A). The protein expression of PHD2 gradually increased after exposure to $\mathrm{CoCl}_{2}$, reaching the peak at $48 \mathrm{~h}$ (Figure 1B). While the PHD2 mRNA level reached its peak at $24 \mathrm{~h}(P<0.01 v s$. “Oh") (Figure 1A).
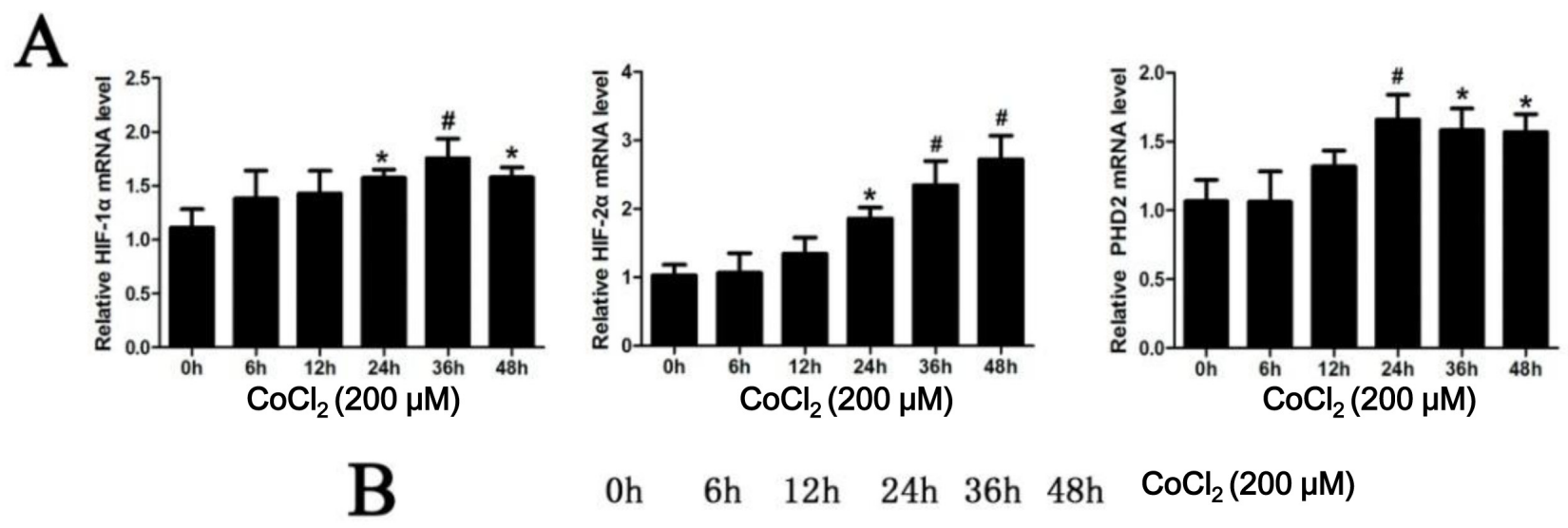

oh $\quad 6 \mathrm{~h} \quad 12 \mathrm{~h} \quad 24 \mathrm{~h} \quad 36 \mathrm{~h} \quad 48 \mathrm{~h} \quad \mathrm{CoCl}_{2}(200 \mu \mathrm{M})$

HIF-1 $\alpha$

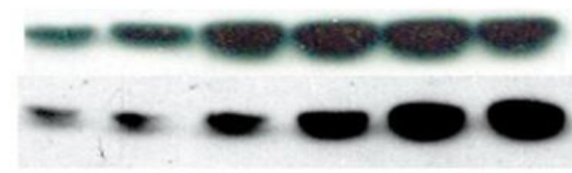

$-120 k D$

HIF-2 $\alpha$

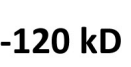

PHD2

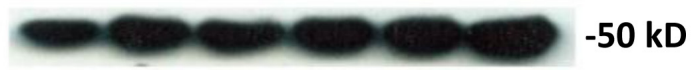

$\beta$-actin
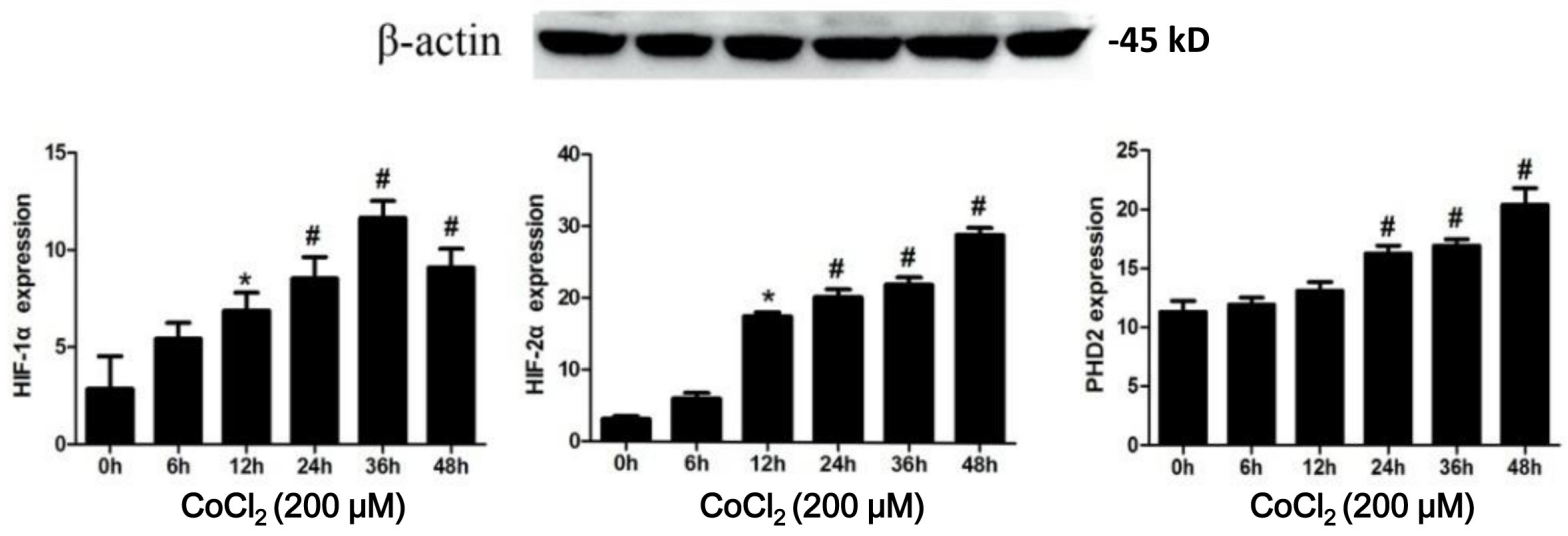

Figure 1: $\mathbf{C o C l}_{2}$ treatment increases expression of $\mathbf{H I F - 1 / 2} \alpha$ and PHD2. A. HK-2 cells were incubated with $200 \mu \mathrm{M}$ of $\mathrm{CoCl}_{2}$ for applied time, mRNA and protein expressions of HIF-1 $\alpha$, HIF-2 $\alpha$ and PHD2 were tested by RT-qPCR assay (A) and Western blot assay B., respectively. HIF-1 $\alpha$, HIF- $2 \alpha$ and PHD2 mRNA expression was normalized to $18 \mathrm{~S}(n=12)$. HIF-1 $\alpha$, HIF-2 $\alpha$ and PHD2 protein expression was normalized to $\beta$-actin $(\mathrm{B}$, lower panels, $n=14)$. ${ }^{*} P<0.05$ vs. 0 h group; $\# P<0.01$ vs. $0 \mathrm{~h}$ group. 
$\mathrm{CoCl}_{2}$ induces apoptosis and autophagy activation in $\mathrm{HK}-2$ cells

Next, we tested the expression of Bcl-xL, a known HIF-1 $\alpha$-regulaed gene [22], in $\mathrm{CoCl}_{2}$-treated HK-2 cells. As shown in Figure 2, the protein expression of Bcl-xL was increased after $\mathrm{CoCl}_{2}$ treatment. It level was peaked at $12-24 \mathrm{~h}$ and was then declined afterwards (Figure 2). We also analyzed the apoptotic response of HK-2 cells to $\mathrm{CoCl}_{2}$. Western blot results in Figure 2 showed that $\mathrm{CoCl}_{2}$ up-regulated the pro-apoptotic Bax [23, 24] in HK-2 cells (Figure 2), suggesting apoptosis activation.

To test whether autophagy could be induced after hypoxia treatment, we investigated the expression of LC3II, whose upregulation is considered as the characteristic marker of autophagy [25]. $\mathrm{CoCl}_{2}$ induced a significant accumulation of LC3 in HK-2 cells. Upregulation of LC3-II was most significant at $12 \mathrm{~h}(P<0.01 v s$. " $0 \mathrm{~h}$ ") after $\mathrm{CoCl}_{2}$ treatment (Figure 2). And its level was then decreased thereafter (Figure 2). We further examined
$\mathrm{CoCl}_{2}$-induced autophagy in $\mathrm{HK}-2$ cells by transmission electron microscope (TEM) (Figure 3). As shown in the representative micrographs, autophagosomes, with characteristic features of double or multiple membranes, began to appear $6 \mathrm{~h}$ after $\mathrm{CoCl}_{2}$ treatment in the HK-2 cells (Figure 3). They were observed up to $48 \mathrm{~h}$ after treatment of $\mathrm{CoCl}_{2}$ (Figure 3). These results indicate that $\mathrm{CoCl}_{2}$ activates autophagy in HK-2 cells.

Autophagy inhibitor 3-MA inhibits HK-2 cell death and apoptosis by $\mathrm{CoCl}_{2}$

To explore the role of autophagy in $\mathrm{CoCl}_{2}$-induced HK-2 cell death, pharmacological strategy was applied. One hour prior to the $\mathrm{CoCl}_{2}$ treatment, we exposed cells to 3-methyladenine (3-MA), which is a selective inhibitor of the autophagy [26]. As shown in Figure 4A and 4B, 3-MA decreased the LC3II/LC3I ratio and increased cell viability compared to the $\mathrm{CoCl}_{2}$ only group (24.91 \pm 1.59 vs. 29.6 $\pm 2.79, P<0.01)$. Further, $\mathrm{CoCl}_{2}$-induced $\mathrm{HK}-2$

\section{$\mathrm{CoCl}_{2}(200 \mu \mathrm{M})$}

\section{Oh $\quad 6 \mathrm{~h} \quad 12 \mathrm{~h} \quad 24 \mathrm{~h} \quad 36 \mathrm{~h} \quad 48 \mathrm{~h}$}
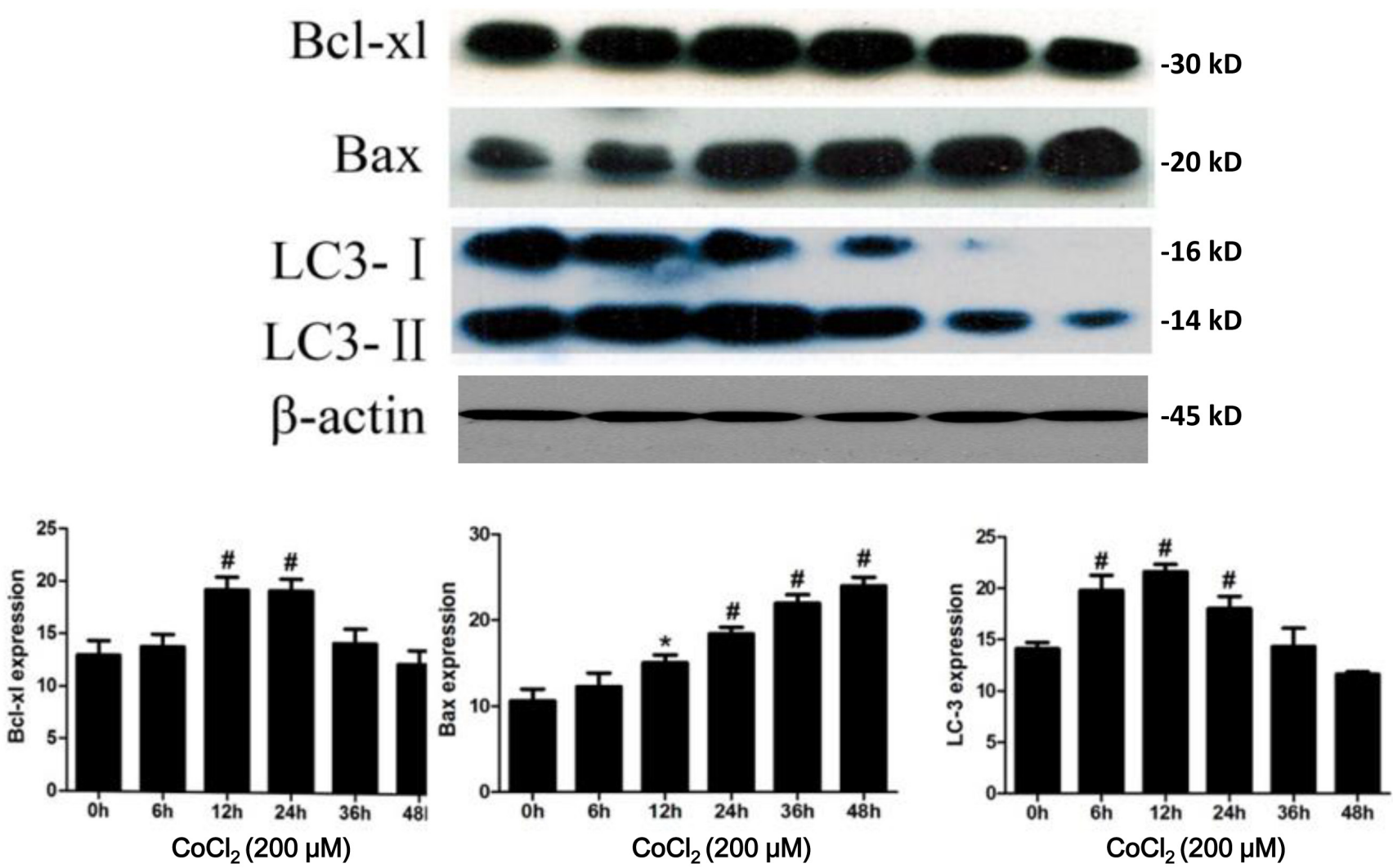

Figure 2: $\mathrm{CoCl}_{2}$ activates apoptosis and autophagy in $\mathbf{H K}-2$ cells. HK-2 cells were incubated with $200 \mu \mathrm{M}$ of $\mathrm{CoCl} \mathrm{C}_{2}$ for applied time, expressions of listed proteins were tested by Western blot assay (Upper panel), protein expression was normalized to $\beta$-actin (low panels, $n=12)$. ${ }^{*} P<0.05$ vs. 0h group; $\# P<0.01$ vs. 0h group. 

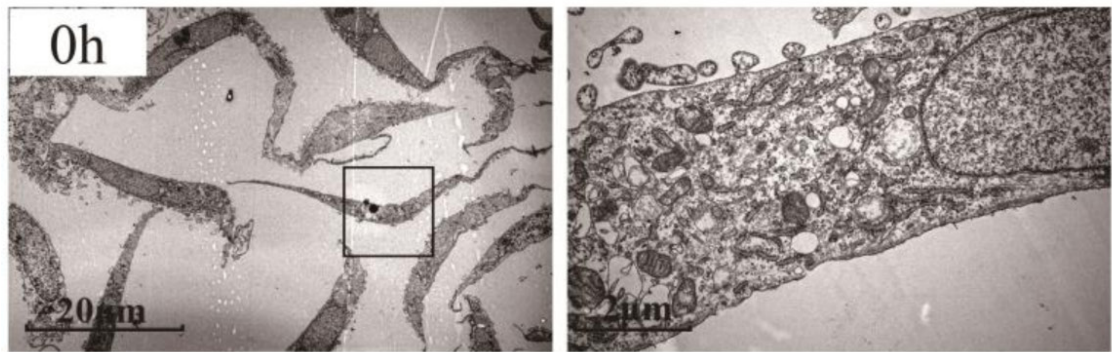

$\mathrm{CoCl}_{2}(200 \mu \mathrm{M})$
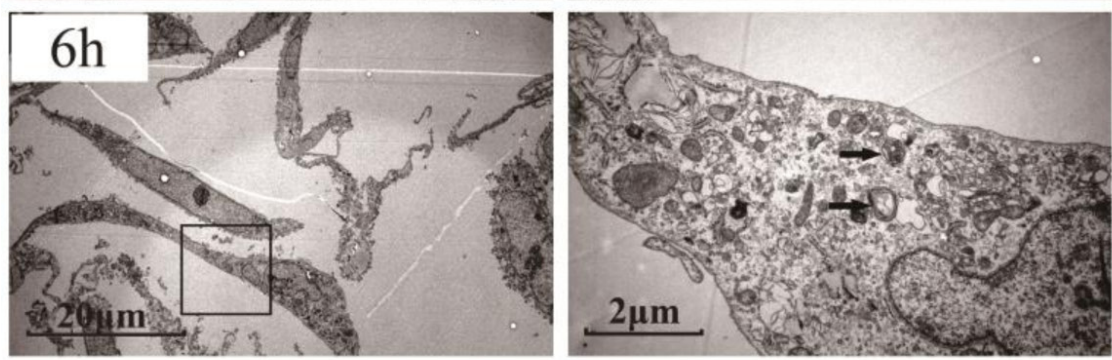

$\mathrm{CoCl}_{2}(200 \mu \mathrm{M})$
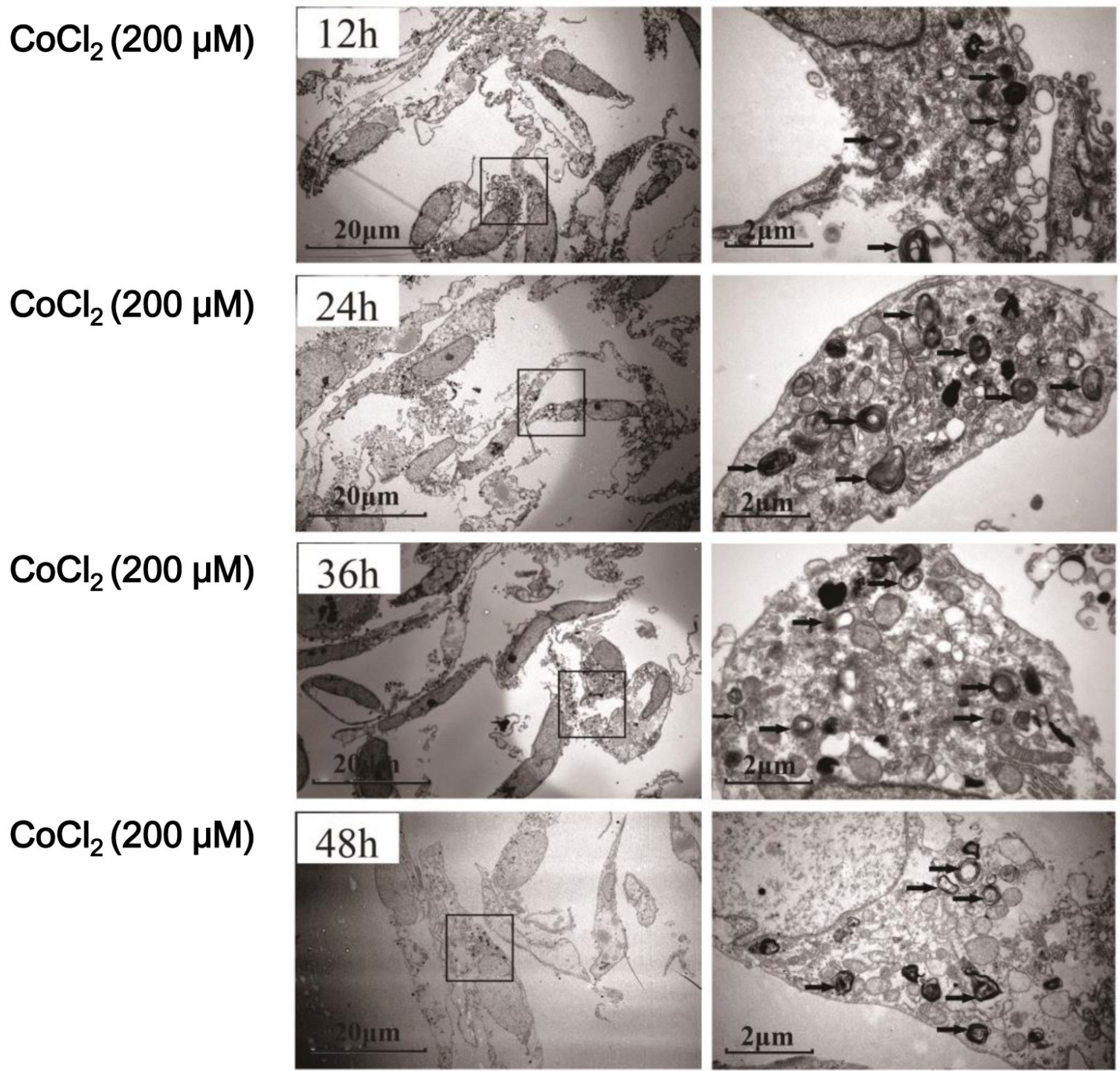

Figure 3: Autophagosome formation in $\mathbf{C o C l}_{2}$-treated $\mathbf{H K}-2$ cells. $\mathrm{HK}-2$ cells were incubated with $200 \mu \mathrm{M} \mathrm{CoCl}_{2}$ for $0-48 \mathrm{~h}$. The cells were then fixed and processed for electron microscopy. Autophagosomes (black arrows) with characteristic double or multiple membranes were identified. Experiments in this figure were repeated four times, and similar results were obtained. 
cell apoptosis, tested by ssDNA ELISA assay, was also attenuated by the pretreatment of 3-MA (Supplementary Figure 1A). Additionally, under electron microscopy, the number of autophagosomes decreased and the cell ultrastructure appeared relatively normal (Figure 4C). These results suggested that the autophagic process may be harmful to human renal tubular epithelial cells during $\mathrm{CoCl}_{2}$-induced hypoxia.

\section{PHD2 silencing in HK-2 cells attenuates apoptosis and autophagy by $\mathrm{CoCl}_{2}$}

PHD2 is the critical oxygen sensor of HIF-1 $\alpha[8$, 9]. In order to determine the role of PHD2 in autophagy during $\mathrm{CoCl}_{2}$ treatment, small interference RNA (siRNA) strategy was applied to knockdown PHD2 in HK-2 cells. Following PHD2 siRNA transfection, mRNA and protein expression of PHD2 decreased by $79 \%$ (3.13 \pm 0.25 vs. $0.66 \pm 0.11, P<0.01)$ and $61 \%(11.00 \pm 1.00$ vs. $4.32 \pm$ $0.80, P<0.01$ ) respectively (Figure $5 \mathrm{~A}$ and $5 \mathrm{~B}$ ). HIF$1 \alpha$ protein level was increased by $27 \%(9.57 \pm 0.72$ vs. 12 $\pm 0.42, P<0.01$ ) (Figure 5B). Yet, there was little change on HIF-2 $\alpha$ expression in the same condition (Figure $5 \mathrm{~B}$ ). Intriguingly, PHD2 siRNA up-regulated Bcl-xL, whiling downregulation Bax in HK-2 cells (Figure 5B). Further,
Western blot assay revealed that the pattern of LC3II/ LC3I expression in the PHD2 siRNA cells was consistent with the 3-MA-treated cells. PHD2 siRNA decreased LC3II expression in $\mathrm{CoCl}_{2}$-treated $\mathrm{HK}-2$ cells (Figure $5 \mathrm{~B})$. We also studied the influence of silencing PHD2 on cell viability under hypoxia. As shown in Figure 5C, PHD2 siRNA protected $\mathrm{HK}-2$ cells from $\mathrm{CoCl}_{2}$ insults (cell viability, $28.32 \pm 2.41$ vs. $37.04 \pm 3.25, P<0.01$ ). Meanwhile, $\mathrm{CoCl}_{2}$-induced $\mathrm{HK}-2$ cell apoptosis was also inhibited by PHD2 siRNA (Supplementary Figure 1B). These results demonstrate that, in $\mathrm{CoCl}_{2}$-treated $\mathrm{HK}-2$ cells, PHD2 silencing facilitates HIF-1 $\alpha$ expression, and exerts cyto-protective effect possibly via inhibiting apoptosis and autophagy. In line with these findings, we showed that L-mimosine (L-Mim), a non-selective PHD inhibitor [27], also inhibited $\mathrm{CoCl}_{2}$-induced viability reduction (Supplementary Figure 1C) and apoptosis activation (Supplementary Figure 1D) in HK-2 cells.

\section{HIF-1 $\alpha$ knockdown abolishes cytoprotection by PHD2 siRNA in $\mathrm{CoCl}_{2}$-treated $\mathrm{HK}-2$ cells}

To further investigate the molecular mechanisms of PHD2/HIF on cell survival under hypoxia, HK-2 cells were co-treated with PHD2 siRNA and HIF-1 $\alpha$ siRNA. As
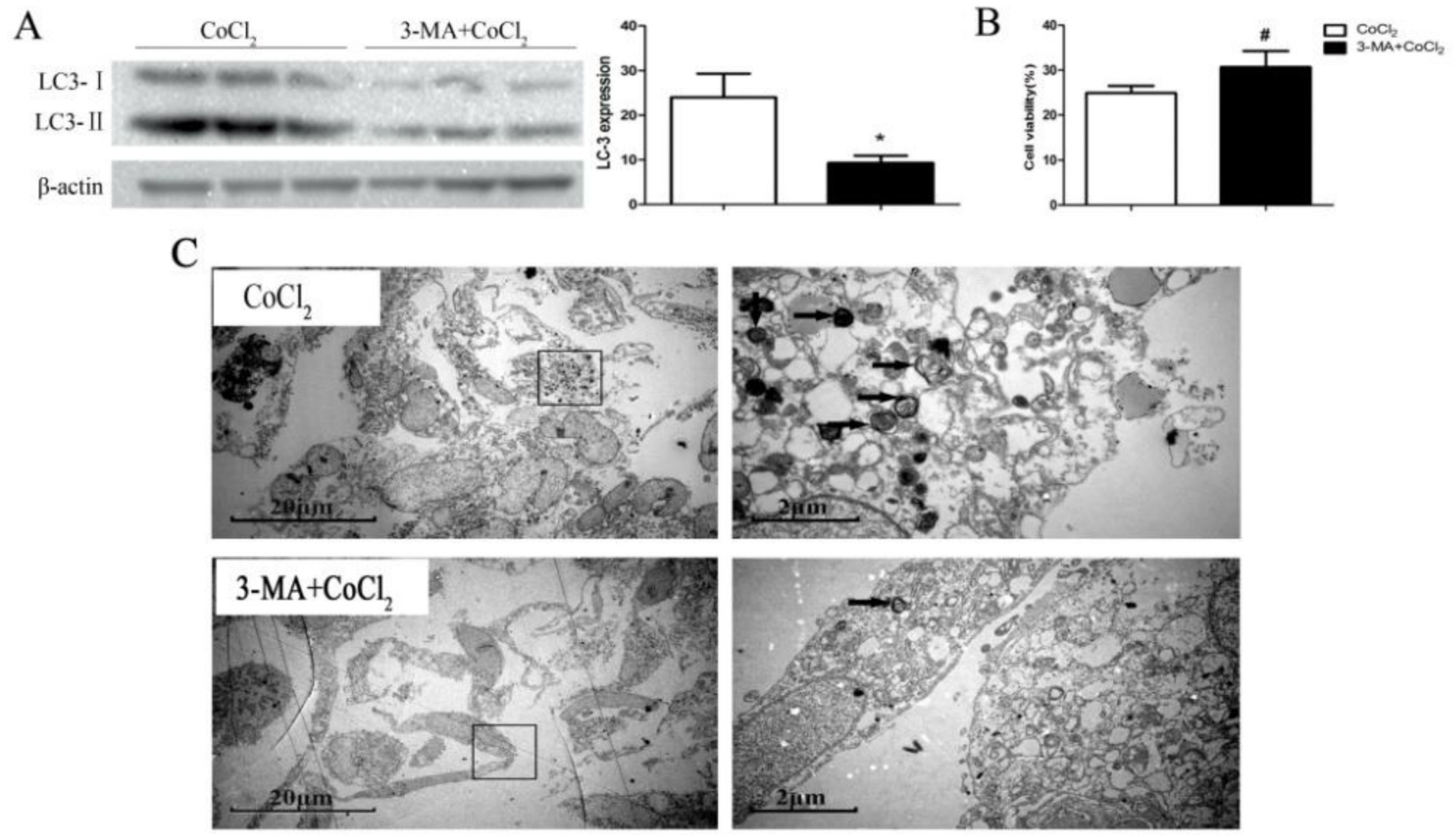

Figure 4: Autophagy inhibitor 3-MA inhibits $\mathbf{H K}-2$ cell death by $\mathbf{C o C l}_{2}$. HK-2 cells were pre-incubated with 3-MA (5 mM) for $1 \mathrm{~h}$ before $\mathrm{CoCl}_{2}(200 \mu \mathrm{M})$ treatment. Samples were collected $24 \mathrm{~h}$ after treatment, expressions of listed proteins were tested by Western blot assay A; Relative cell viability (vs. untreated control cells) was evaluated with Alamar Blue analysis B. Electron micrograph images showed the ultrastructure of cells with indicated treatment. ${ }^{*} P<0.01 v s . \mathrm{CoCl}_{2}$ only group; $\# P<0.05 v s$. $\mathrm{CoCl}_{2}$ only group. 
A

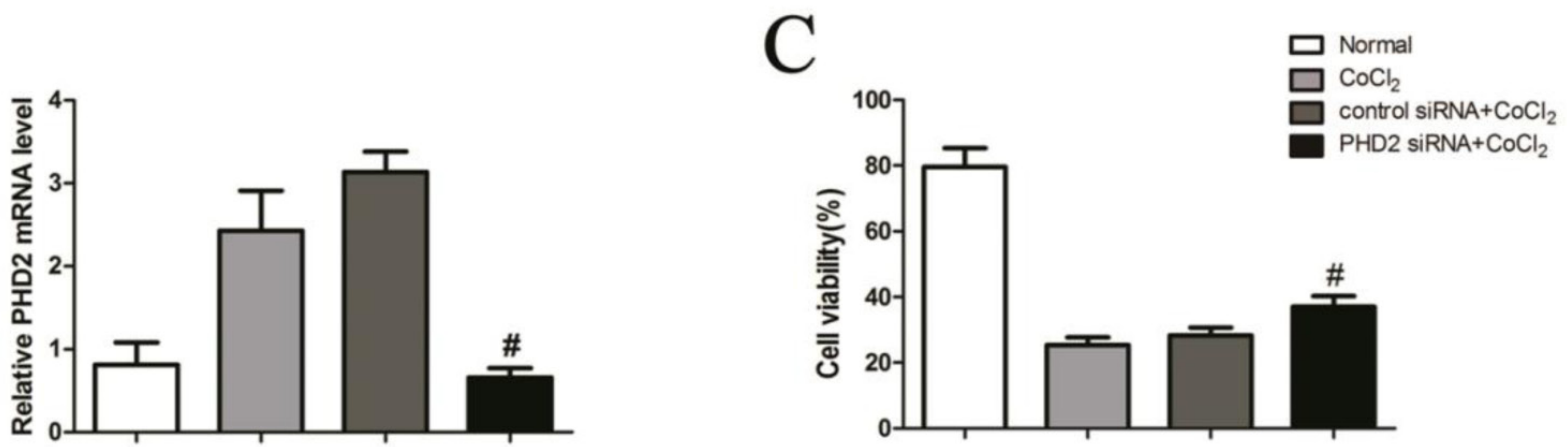

B
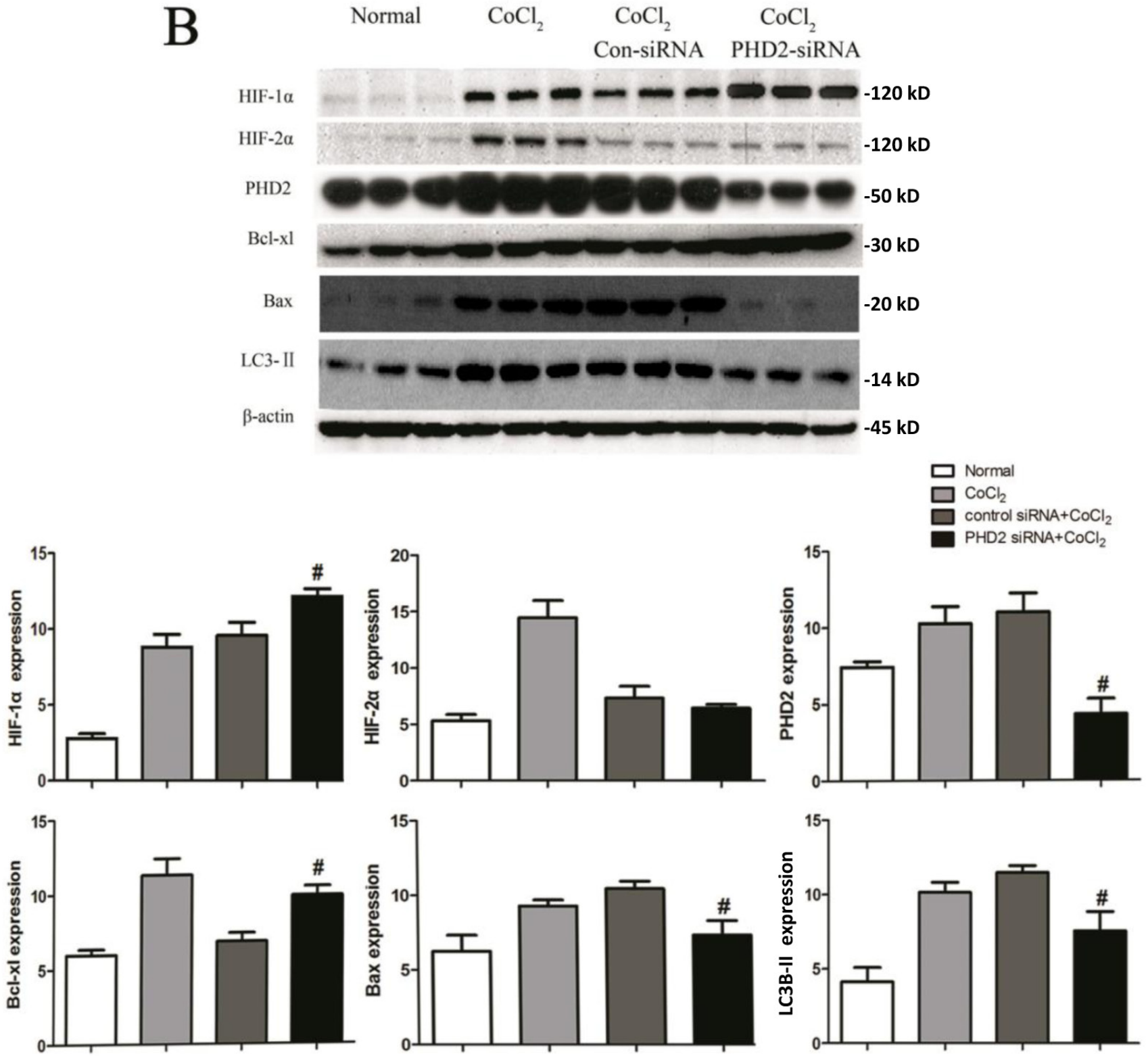

Figure 5: PHD2 silencing in HK-2 cells attenuates apoptosis and autophagy by $\mathrm{CoCl}_{2}$. $\mathrm{HK}-2$ cells transfected with indicated siRNA were treated with or without $\mathrm{CoCl}_{2}(200 \mu \mathrm{M})$ for $24 \mathrm{~h}$, PHD2 mRNA expression was tested by RT-qPCR assay A; Expressions of listed proteins were tested by Western blot assay B; Relative cell viability (vs. untreated control cells) was evaluated with Alamar Blue analysis $\mathbf{C}$. Protein expression was normalized to $\beta$-actin (low panels, $n=12$ ). ${ }^{*} P<0.01 v s$. Con-siRNA group. 

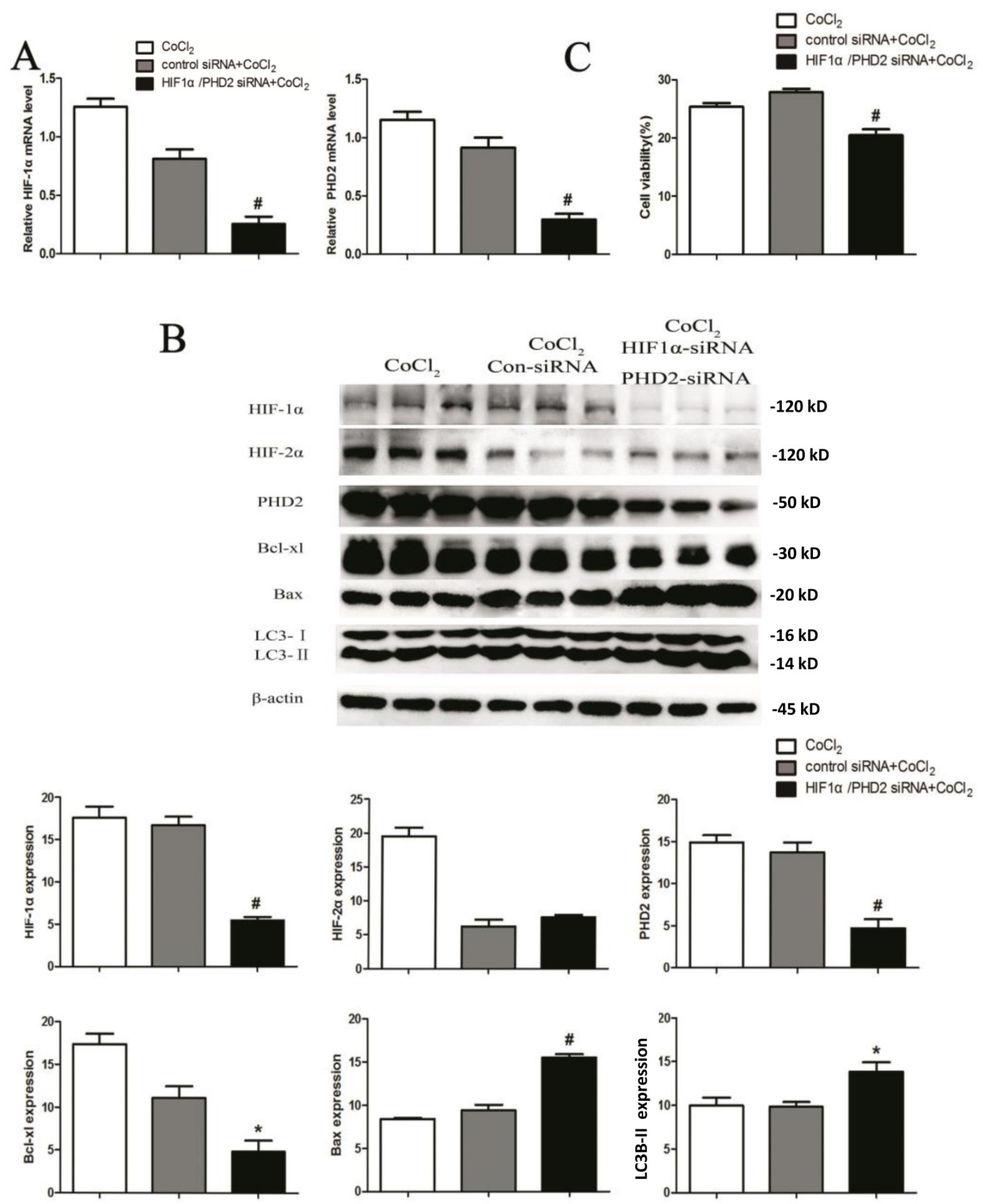

Figure 6: HIF-1 $\alpha$ knockdown abolishes cytoprotection by PHD2 siRNA in $\mathrm{CoCl}_{2}$-treated HK-2 cells. HK-2 cells were transfected with applied siRNA (Control siRNA, HIF-1 $\alpha$ siRNA or PHD2 siRNA), cells were then treated with $\mathrm{CoCl}_{2}(200 \mu \mathrm{M})$ for $24 \mathrm{~h}$, expressions of listed proteins and mRNAs were shown A. and B. Relative cell viability (vs. untreated control cells) was evaluated with Alamar Blue analysis C. Protein expression was normalized to $\beta$-actin (low panels, $n=12$ ). ${ }^{\#} P<0.01 v s$. Con-siRNA group (A-C). 
shown in Figure 6A, mRNA levels of PHD2 and HIF-1 $\alpha$ were decreased by $68 \%$ and $69 \%$, respectively $(0.91 \pm 0.12$ vs. $0.29 \pm 0.09,0.81 \pm 0.22$ vs. $0.25 \pm 0.19 ; P<0.01) 24 \mathrm{~h}$ after corresponding siRNA transfection. Protein level of PHD2 and HIF- $1 \alpha$ were also decreased by $66 \%$ and $67 \%$ $(P<0.01)$ (Figure 6B). Simultaneously, silencing PHD2 and HIF-1 $\alpha$ also down-regulated Bcl-xL protein $(P<0.05)$, yet up-regulating $\operatorname{Bax}(P<0.01)$ and LC3II expression $(P$ $<0.05)$. Importantly, HIF-1 $\alpha$ siRNA knockdown almost abolished cytoprotection by PHD2 siRNA in $\mathrm{CoCl}_{2}$-treated HK-2 cells (Figure 6C).

\section{L-mimosine administration attenuates renal ischemia-reperfusion injuries}

To study the role of PHD2 in vivo, we applied a non-selective PHD inhibitor L-mimosine. Animals in the
L-mimosine group (50mg/kg body, 6h before surgery) showed improved renal function compared to those in the vehicle group, and the serum level of creatinine was dramatically decreased in L-mimosine-treated mice (Figure 7A). Histological examinations revealed significant tubular damage and a high injury score in the injured kidney $24 \mathrm{~h}$ after surgery, which were largely inhibited by L-mimosine pretreatment. (Figure 7B).

For the signaling studies, we showed that L-mimosine administration augmented HIF-1/2 $\alpha$ accumulation after ischemia (Figure 7C). HIF-1 $\alpha$ and HIF-2 $\alpha$ protein expression in kidney increased by $35.4 \%$ (32.18 \pm 4.75 vs. $49.84 \pm 7.14, P<0.05)$ and $35.5 \%$ (37.02 \pm 8.06 vs. $57.42 \pm 9.44, P<0.05)$ respectively with L-mimosine treatment (Figure 7C). Conversely, the expression of PHD2 was significantly decreased by $76.0 \%$ $(61.46 \pm 5.89$ vs. $14.78 \pm 3.79, P<0.01)$ after L-mimosine treatment.
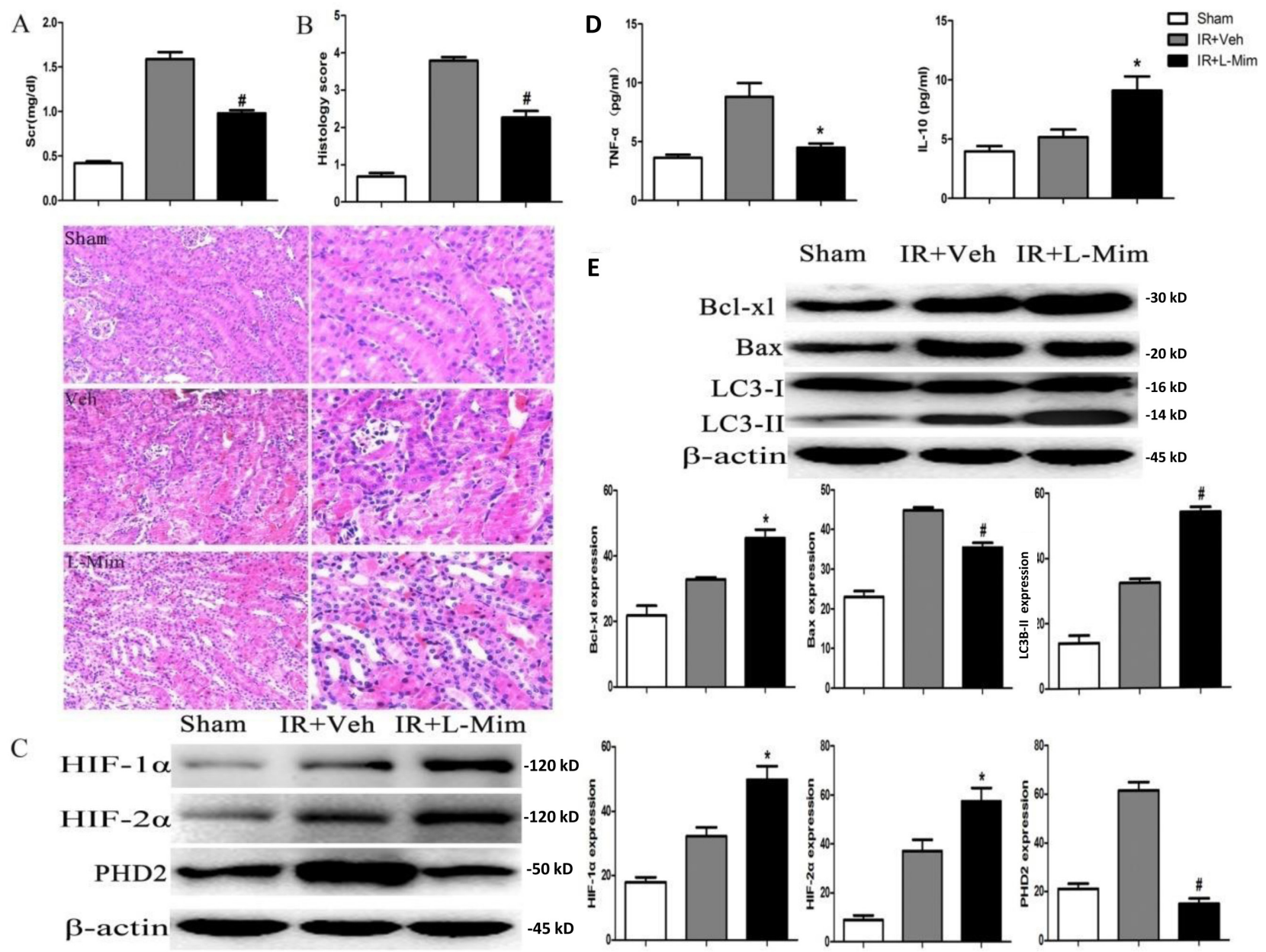

Figure 7: L-mimosine administration attenuates renal ischemia-reperfusion injuries. The $6-8$ week male $\mathrm{C} 57 \mathrm{BL} / 6 \mathrm{~J}$ mice, pretreated with L-mimosine (L-Mim, $50 \mathrm{mg} / \mathrm{kg}$, "IR+L-Mim") or vehicle control (10\% $\mathrm{NaHCO}_{3}$, "IR+Veh"), were subjected to ischemia reperfusion operation. After $24 \mathrm{~h}$, serum creatinine (Scr) level was analyzed A; HE staining were performed on kidney slices, and History scores were calculated $\mathbf{B}$; Expressions of listed proteins in fresh kidney slices were tested by Western blot $\mathbf{C}$. and $\mathbf{E}$; Level of TNF- $\alpha$ and IL-10 in the fresh kidney slices was tested by ELISA assay D. Sham-operated mice served as controls. Protein expression was normalized to $\beta$-actin $(n=10) .{ }^{*} P<0.05 v s$. "IR+Veh" group $(\mathrm{C}-\mathrm{F}) ;{ }^{\#} P<0.01$ vs. "IR+Veh" group $(\mathrm{C}-\mathrm{F})$; 
ELISA analysis results demonstrated that, with the L-mimosine pre-treatment, the level of inflammatory cytokine TNF- $\alpha$ was markedly decreased, yet the antiinflammatory cytokine IL-10 was up-regulated (Figure 7D). The above apoptosis and autophagy markers along with inflammatory cytokine levels were also tested in vivo. The quantitative analysis revealed that expression of the anti-apoptotic protein Bcl-xL in kidney was upregulated, but the pro-apoptotic protein Bax was downregulated following L-mimosine administration (Figure 7E). Further, conversion of LC3-I to LC3-II was upregulated by L-mimosine treatment, indicating autophagy augmentation (Figure 7E). Collectively, we showed that pretreatment with L-mimosine markedly attenuated the deterioration of renal function and the severity of renal damage. Molecularly, L-mimosine inhibited apoptosis, facilitated autophagy and suppressed inflammatory responses in injured kidney.

\section{DISCUSSION}

The main findings of our study are as follows: PHD2 siRNA knockdown produced a renoprotective effect by attenuating apoptosis and autophagy in HK-2 cells. Further, L-mimosine-activated HIF offered significant protection by attenuating apoptosis, enhancing autophagy and suppressing inflammatory responses in mice.

We showed that treatment of $\mathrm{CoCl}_{2}$, a hypoxia mimic, in HK-2 tubular epithelial cells induced PHD2 and HIF-1/2 $\alpha$ expression. siRNA knockdown of PHD2 protected $\mathrm{HK}-2$ cells from $\mathrm{CoCl}_{2}$ possibly though facilitating HIF-1 $\alpha$ expression. Reversely, HIF- $1 \alpha$ siRNA knockdown almost abolished cytoprotection by PHD2 siRNA in $\mathrm{CoCl}_{2}$-treated HK-2 cells. Therefore, target HIF$1 \alpha$ by modulating PHD2 could offer protection of tubular epithelial cells in hypoxia conditions.

Autophagy could be cell detrimental or cytoprotective depending on the stimuli that provoked it. It is still largely unknown what mechanisms determine the final outcomes [14-16]. Here, we observed that $\mathrm{CoCl}_{2}$ activated autophagy in HK-2 cells. On the other hand, 3-MA, the autophagy inhibitor, blocked autophagy and protected $\mathrm{HK}-2$ cells from $\mathrm{CoCl}_{2}$. These results indicate that the autophagic pathway may act as a detrimental factor in the $\mathrm{CoCl}_{2}$ hypoxic model at least in vitro, although more detailed studies are still needed.

Interestingly, our in vivo results demonstrated that autophagy induction was accompanied with improved kidney functions. These results indicated that autophagy may play a protective role against kidney ischemia reperfusion injuries. These in vivo results are consistent with other studies [28, 29]. The mechanisms underlying the pro-survival effect of autophagy remain largely unknown [28, 30]. In the process of renal ischemia reperfusion injury, autophagy activation was shown to eliminate damaged mitochondria and prevent accumulation of aggregate-prone proteins [28, 29]. The rapid increased number of research publications on autophagy and hypoxia will lead to a better understanding the mechanisms involved.

Collectively, the results of our study suggest that activating HIF, i.e. via inhibiting PHD, may be a useful therapeutic strategy in ischemic renal injury.

\section{MATERIALS AND METHODS}

\section{Cell culture and treatment}

HK-2, a human kidney epithelial cell line [31], was purchased from American Type Culture Collection (Manassas, VA). Cells were cultured in DMEM/F12 (Gibco, Invitrogen, USA) with $10 \%$ fetal bovine serum (FBS, Gibco, Invitrogen, USA) under $5 \% \mathrm{CO}_{2}$ and $95 \%$ air atmosphere at $37^{\circ} \mathrm{C}$. Cells were plated onto $35-\mathrm{mm}$ dishes at a density of $\sim 0.5 \times 10^{6}$ cells $/$ dish until $70-80 \%$ confluent for experiment.

\section{PHD2 and HIF-1 $\alpha$ gene silencing}

Small interfering RNA (siRNA) sequences against HIF-1 $\alpha$, PHD2 and a scrambled control siRNA were designed and synthesized by GenePharma (GenePharma, Shanghai, China). siRNAs were transfected using DharmaFECT 1 (Dharmacon, Shanghai, China) as previously described [32]. Transfected cells were incubated at $37^{\circ} \mathrm{C}$ for $24 \mathrm{~h}$. Protein and RNA expressions were analyzed Western blot and RT-qPCR respectively.

\section{Protein extraction}

Cells were grown to $70-80 \%$ confluence and stimulated with $200 \mu \mathrm{M} \mathrm{CoCl}_{2}$ for the indicated time period. Afterwards, cells were placed on ice immediately and washed with PBS, and cell lysis was performed using $8 \mathrm{M}$ urea, $10 \%$ glycerol, $10 \mathrm{mM}$ Tris- $\mathrm{HCl}$ (pH 6.8), 1\% SDS, 5mM dithiothreitol, and the Complete Mini ProteaseInhibitor Cocktail (Roche, Mannheim, Germany). After being centrifuged at $12,000 \mathrm{~g}$ for $15 \mathrm{~min}$ at $4^{\circ} \mathrm{C}$, the supernatant was collected, and protein concentrations were determined. The protein concentration was determined by using a Bio-Rad Bradford protein assay kit (BioRad, Shanghai, China). HIF-1 $\alpha$ antibody (3716), HIF- $2 \alpha$ antibody (7096), PHD antibody (3293), Bax antibody (2772), Bcl-xL antibody (2762), LC3B antibody (2775) and $\beta$-actin antibody (3700) were purchased from Cell Signaling Tech (Shanghai, China). Band intensity (total gray) was quantified via the ImageJ software (NIH), the values were always normalized to corresponding loading control. 


\section{Assay of cell viability}

For cell viability assessment, $10 \mu \mathrm{L}$ of Alamar Blue (Kaiji, Nanjing, China) was added to each well and the plates were incubated at $37^{\circ} \mathrm{C}$ and $5 \% \mathrm{CO}_{2}$ for $2 \mathrm{~h}$. The absorbance was measured by using a Synergy HT multidetection microplate reader (Bio-Tek, Winooski, VT) at a test wavelength of $570 \mathrm{~nm}$.

\section{Apoptosis assay by single strand DNA (ssDNA) ELISA}

DNA denature is an important characteristic marker of cell apoptosis. Following the treatment of cells, denatured ssDNA was detected through a nucleosomal monoclonal antibody in an ELISA format. Briefly, cells $\left(1 \times 10^{4} /\right.$ well $)$ were seeded onto 96 -well plates. Cell apoptosis was analyzed by the ssDNA ELISA kit from Chemicon International (Temecula, CA, Catalog Number: 1217). OD value at $450 \mathrm{~nm}$ was utilized as a quantitative indicator of cell apoptosis.

\section{Electron microscopy}

Cells were grown in T25 flasks and fixed for $4 \mathrm{~h}$ in $2.5 \%$ glutaraldehyde fixative in phosphate buffer at $4^{\circ} \mathrm{C}$. After fixation, cell monolayers were placed in glutaraldehyde wash solution and then post-fixed in Millonigs Osmium Tetroxide fixative for 15-30 minutes. The cultures were dehydrated through a graded series of $10 \%$ to $100 \%$ ethanol, infiltrated, and then embedded in TAAB Premix Resin medium. Ultrathin sections were collected on copper grids and stained with uranyl acetate and lead citrate. Sections were viewed using a Hitachi H7600 transmission electron microscope (TEM).

\section{Real-time reverse transcription-polymerase chain reaction (RT-qPCR)}

Total RNA of HK-2 cells was extracted using Trizol reagents (Invitrogen, Carlsbad, CA). Extracted RNA was reverse-transcribed to complementary DNA (PrimeScript; TaKaRa, Kyoto, Japan), which was utilized for realtime polymerase chain reaction (PCR) (SYBR reagents, TaqTMTaKaRa). PCR primers (Sangon, Shanghai, China) were designed with the following sequences: HIF$1 \alpha$ forward: 5'-CGGAGGTGTTCTATGAGCTGG-3', reverse: 5'-AGCTTGTGTGTTCGCAGGAA-3'. HIF$2 \alpha$ forward: 5'-CGGAGGTGTTCTATGAGCTGG-3', reverse: 5'-AGCTTGTGTGTTCGCAGGAA-3'. PHD2 forward: 5'-AGGCGATAAGATCACCTGGAT-3', reverse: 5'-TTCGTCCGGCCATTGATTTTG-3'; 18s forward: 5'-CGGCTACCACATCCAGAA-3', reverse: 5'-CCTGTATTGTTATTTTTCGTCACTACCT-3'. 18s
mRNA was tested as endogenous control for desired mRNAs. The relative gene expressions were calculated in accordance with the ${ }^{\Delta \Delta} \mathrm{Ct}$ method [33]. Relative mRNA levels were expressed as $2^{-\Delta \Delta} \mathrm{Ct}$ and ratios to internal control.

\section{Mouse renal ischemia reperfusion injury}

Experiments were performed on 6-8 week male C57BL/6J mice weighing 20-22 g (from Animal Center of Fudan University, Shanghai, China). Animals were housed in temperature- and humidity-controlled cages, with free access to water and rodent food on a 12-h light/dark cycle. All protocols were approved by the Institutional Animal Care and Use Committee of Fudan University, and adhered strictly to the NIH Guide for the Care and Use of Laboratory Animals. All surgery was performed under sodium pentobarbital anesthesia, and efforts were made to minimize suffering. L-mimosine (L-Mim, Sigma, Dorset, UK) was resolved in $10 \% \mathrm{NaHCO}_{3}$ at a concentration of $15 \mathrm{mg} / \mathrm{mL}$ (adjusted $\mathrm{pH}$ to 7.4 by $\mathrm{HCl}$ plus PBS) and administered intraperitoneally at $50 \mathrm{mg} / \mathrm{kg}$, 6h before renal ischemia reperfusion injury surgery.

Mice were anesthetized with intraperitoneal sodium pentobarbital $(30 \mathrm{mg} / \mathrm{kg})$, and renal ischemia reperfusion injury was induced by bilateral renal pedicle clamping for $35 \mathrm{~min}$. Sham-operated mice underwent the same surgical procedures but with no occlusion of the renal pedicle. Intra-rectal temperature of mice was maintained at $36.5^{\circ}$ $37.0^{\circ} \mathrm{C}$ with a heating pad. Blood and kidney samples of all mouse groups were harvested at $24 \mathrm{~h}$ after the surgery. Animals were divided into three groups $(n=4)$ : Group 1 (Sham): Sham-operated animals without induction of ischemia reperfusion injury; Group 2 (Veh): Animals pretreated with $\mathrm{NaHCO}_{3}(\mathrm{PH} 7.4) 6 \mathrm{~h}$ before of ischemia reperfusion injury; Group 3 L-mimosine (L-Mim, Sigma, M0253, Shanghai, China) treatment group: Animals pretreated with L-Mim $6 \mathrm{~h}$ before of ischemia reperfusion injury;

\section{Measurement of renal functions and histological analysis}

Blood samples were obtained at time of sacrifice for measurement of serum creatinine (Scr). Scr level was determined using the Quantichrom Creatinine Assay Kit (DICT-500, Universal Biologicals, Shanghai, China), following the manufacturer's protocol. Kidney slices were embedded in paraffin wax, sectioned at $4 \mu \mathrm{m}$ and stained with hematoxylin and eosin (HE) with standard methods. Histopathological scoring was performed in a blinded manner by a pathologist without knowing the experimental protocol. Severity of tubular injury was scored on a semi-quantitative scale: " 0 " = normal, " 1 " = $10-25 \%, " 2 "=26-50 \%, " 3 "=51-75 \%$, and " $4 "=>75 \%$. 
At least 10 consecutive fields in the corticomedullary junction and outer medulla were examined under $\times 400$ magnification (Lecia, DM6000 B, Germany).

\section{Enzyme-linked immunosorbent assay (ELISA)}

The levels of pro-inflammatory factor tumor necrosis factor- $\alpha$ (TNF- $\alpha)$ and anti-inflammatory cytokine Interleukin-10 (IL-10) were measured by ELISA (MBS495354 for TNF- $\alpha$, and MBS288580 for IL-10, BioSource, Shanghai, China). Photometric measurements were conducted at $450 \mathrm{~nm}$ via a microplate reader (BioRad).

\section{Western blot assay}

Protein lysates $(30 \mu \mathrm{g}$ protein per sample) were loaded and separated on sodium dodecyl sulfatepolyacrylamide gels (SDS-PAGE) and then transferred to a polyvinylidene difluoride (PVDF) membrane. The membrane was blocked with $5 \%$ nonfat milk and incubated with primary antibodies and corresponding second antibodies. Following primary antibodies were utilized in this study: HIF-1 $\alpha$ (mouse monoclonal 1:500; Abcam, Cambridge, UK), HIF-2 $\alpha$ (rabbit monoclonal 1:500; Novus, Littleton, CO), PHD2 (rabbit monoclonal 1:1500; Novus, Littleton, CO), Bcl-xL (rabbit monoclonal 1:1,000; Cell Signaling Technology, Danvers, MA), Bax (rabbit monoclonal 1:1,000; Cell Signaling Technology, Danvers, MA) or Light chain 3 (LC-3, rabbit monoclonal 1:1,000; Cell Signaling Technology, Danvers, MA).

\section{Statistical analysis}

Statistical analysis was performed using the statistical software SPSS Version 20.0 (SPSS Inc., Chicago, IL). Data were analyzed using the $t$ test when comparing two groups and one-way ANOVA followed by Tukey $t$-test for the time course data. $P<0.05$ was considered significant. Data were shown as mean \pm SEM.

\section{CONFLICTS OF INTEREST}

The authors declare no competing or financial interests related to the submission of this work

\section{GRANT SUPPORT}

This work was supported by the Projects of Science and Technology. Commission of Shanghai Municipality (14DZ2260200, the project of Shanghai Key Laboratory of Kidney and Blood Purification) and National Natural Science Foundation of China(81430015, 81270779).

\section{REFERENCES}

1. Fang $\mathrm{Y}$, Teng $\mathrm{J}$ and Ding $\mathrm{X}$. Acute kidney injury in China. Hemodial Int. 2015; 19:2-10.

2. Thadhani R, Pascual $M$ and Bonventre JV. Acute renal failure. N Engl J Med. 1996; 334:1448-1460.

3. Nangaku M, Rosenberger C, Heyman SN and Eckardt KU. Regulation of hypoxia-inducible factor in kidney disease. Clin Exp Pharmacol Physiol. 2013; 40:148-157.

4. Andringa KK and Agarwal A. Role of hypoxia-inducible factors in acute kidney injury. Nephron Clin Pract. 2014; 127:70-74.

5. Carmeliet P, Dor Y, Herbert JM, Fukumura D, Brusselmans K, Dewerchin M, Neeman M, Bono F, Abramovitch R, Maxwell P, Koch CJ, Ratcliffe P, Moons L, Jain RK, Collen $\mathrm{D}$ and Keshert E. Role of HIF-1alpha in hypoxia-mediated apoptosis, cell proliferation and tumour angiogenesis. Nature. 1998; 394:485-490.

6. Semenza GL. Hypoxia-inducible factor 1: master regulator of O2 homeostasis. Curr Opin Genet Dev. 1998; 8:588-594.

7. Maxwell PH, Wiesener MS, Chang GW, Clifford SC, Vaux EC, Cockman ME, Wykoff CC, Pugh CW, Maher ER and Ratcliffe PJ. The tumour suppressor protein VHL targets hypoxia-inducible factors for oxygen-dependent proteolysis. Nature. 1999; 399:271-275.

8. Appelhoff RJ, Tian YM, Raval RR, Turley H, Harris AL, Pugh CW, Ratcliffe PJ and Gleadle JM. Differential function of the prolyl hydroxylases PHD1, PHD2, and PHD3 in the regulation of hypoxia-inducible factor. J Biol Chem. 2004; 279:38458-38465.

9. Berra E, Benizri E, Ginouves A, Volmat V, Roux D and Pouyssegur J. HIF prolyl-hydroxylase 2 is the key oxygen sensor setting low steady-state levels of HIF-1alpha in normoxia. EMBO J. 2003; 22:4082-4090.

10. Xi L, Taher M, Yin C, Salloum F and Kukreja RC. Cobalt chloride induces delayed cardiac preconditioning in mice through selective activation of HIF-1alpha and AP-1 and iNOS signaling. Am J Physiol Heart Circ Physiol. 2004; 287:H2369-2375.

11. Matsumoto M, Makino Y, Tanaka T, Tanaka H, Ishizaka $\mathrm{N}$, Noiri E, Fujita $\mathrm{T}$ and Nangaku M. Induction of renoprotective gene expression by cobalt ameliorates ischemic injury of the kidney in rats. J Am Soc Nephrol. $2003 ; 14: 1825-1832$.

12. Kapitsinou PP and Haase VH. Molecular mechanisms of ischemic preconditioning in the kidney. Am J Physiol Renal Physiol. 2015; 309:F821-834.

13. Bellomo R, Kellum JA and Ronco C. Acute kidney injury. Lancet. 2012; 380:756-766.

14. Maiuri MC, Zalckvar E, Kimchi A and Kroemer G. Selfeating and self-killing: crosstalk between autophagy and apoptosis. Nat Rev Mol Cell Biol. 2007; 8:741-752.

15. Marino G, Niso-Santano M, Baehrecke EH and Kroemer G. Self-consumption: the interplay of autophagy and apoptosis. 
Nat Rev Mol Cell Biol. 2014; 15:81-94.

16. Kim KH and Lee MS. Autophagy-a key player in cellular and body metabolism. Nat Rev Endocrinol. 2014.

17. Bellot G, Garcia-Medina R, Gounon P, Chiche J, Roux D, Pouyssegur J and Mazure NM. Hypoxia-induced autophagy is mediated through hypoxia-inducible factor induction of BNIP3 and BNIP3L via their BH3 domains. Mol Cell Biol. 2009; 29:2570-2581.

18. Mazure NM and Pouyssegur J. Atypical BH3-domains of BNIP3 and BNIP3L lead to autophagy in hypoxia. Autophagy. 2009; 5:868-869.

19. Kaushal GP and Shah SV. Autophagy in acute kidney injury. Kidney Int. 2016; 89:779-791.

20. Decuypere JP, Ceulemans LJ, Agostinis P, Monbaliu D, Naesens M, Pirenne J and Jochmans I. Autophagy and the Kidney: Implications for Ischemia-Reperfusion Injury and Therapy. Am J Kidney Dis. 2015; 66:699-709.

21. Huber TB, Edelstein CL, Hartleben B, Inoki K, Jiang M, Koya D, Kume S, Lieberthal W, Pallet N, Quiroga A, Ravichandran K, Susztak K, Yoshida S and Dong Z. Emerging role of autophagy in kidney function, diseases and aging. Autophagy. 2012; 8:1009-1031.

22. Chen N, Chen X, Huang R, Zeng H, Gong J, Meng W, Lu $\mathrm{Y}$, Zhao F, Wang L and Zhou Q. BCL-xL is a target gene regulated by hypoxia-inducible factor-1 \{alpha\}. J Biol Chem. 2009; 284:10004-10012.

23. Marzo I, Brenner C, Zamzami N, Jurgensmeier JM, Susin SA, Vieira HL, Prevost MC, Xie Z, Matsuyama S, Reed JC and Kroemer G. Bax and adenine nucleotide translocator cooperate in the mitochondrial control of apoptosis. Science. 1998; 281:2027-2031.

24. Narita M, Shimizu S, Ito T, Chittenden T, Lutz RJ, Matsuda $\mathrm{H}$ and Tsujimoto $\mathrm{Y}$. Bax interacts with the permeability transition pore to induce permeability transition and cytochrome c release in isolated mitochondria. Proc Natl Acad Sci U S A. 1998; 95:14681-14686.
25. Kabeya Y, Mizushima N, Ueno T, Yamamoto A, Kirisako T, Noda T, Kominami E, Ohsumi Y and Yoshimori T. LC3, a mammalian homologue of yeast Apg8p, is localized in autophagosome membranes after processing. EMBO J. 2000; 19:5720-5728.

26. Seglen PO and Gordon PB. 3-Methyladenine: specific inhibitor of autophagic/lysosomal protein degradation in isolated rat hepatocytes. Proc Natl Acad Sci U S A. 1982; 79:1889-1892.

27. Zhang X, Yan X, Cheng L, Dai J, Wang C, Han P and Chai Y. Wound healing improvement with PHD-2 silenced fibroblasts in diabetic mice. PLoS One. 2013; 8:e84548.

28. Isaka $\mathrm{Y}$, Kimura $\mathrm{T}$ and Takabatake $\mathrm{Y}$. The protective role of autophagy against aging and acute ischemic injury in kidney proximal tubular cells. Autophagy. 2011; 7:10851087.

29. Brooks C, Wei Q, Cho SG and Dong Z. Regulation of mitochondrial dynamics in acute kidney injury in cell culture and rodent models. J Clin Invest. 2009; 119:12751285.

30. Kimura T, Takabatake Y, Takahashi A, Kaimori JY, Matsui I, Namba T, Kitamura H, Niimura F, Matsusaka T, Soga T, Rakugi $\mathrm{H}$ and Isaka Y. Autophagy protects the proximal tubule from degeneration and acute ischemic injury. J Am Soc Nephrol. 2011; 22:902-913.

31. Komoike $\mathrm{Y}$, Inamura $\mathrm{H}$ and Matsuoka M. Effects of salubrinal on cadmium-induced apoptosis in HK-2 human renal proximal tubular cells. Arch Toxicol. 2012; 86:37-44.

32. Reynolds A, Anderson EM, Vermeulen A, Fedorov Y, Robinson K, Leake D, Karpilow J, Marshall WS and Khvorova A. Induction of the interferon response by siRNA is cell type- and duplex length-dependent. RNA. 2006; 12:988-993.

33. Livak KJ and Schmittgen TD. Analysis of relative gene expression data using real-time quantitative PCR and the 2(-Delta Delta C(T)) Method. Methods. 2001; 25:402-408. 